\title{
Análisis para la obtención de hidrógeno a partir de biogás proveniente de la fermentación de bebidas naturales
}

\author{
Analysis for Obtaining Hydrogen from Biogas by Means of the Fermentation of \\ Natural Beverages
}

\author{
Rivera-Vargas Griselda Argelia \\ Instituto Politécnico Nacional \\ Centro de Investigación y de Estudios Avanzados \\ Programa de Doctorado en Desarrollo Científico y \\ Tecnológico para la Sociedad \\ Correo:agrivera@cinvestav.mx \\ Yasuhiro Matsumoto-Kuwabara \\ Instituto Politécnico Nacional \\ Centro de Investigación y de Estudios Avanzados \\ Departamento de Ingeniería Eléctrica \\ Correo:ymatsumo@cinvestav.mx
}

\author{
Baquero-Parra Rafael \\ Instituto Politécnico Nacional \\ Centro de Investigación y de Estudios Avanzados \\ Departamento de Física \\ Correo: rbaquero@fis.cinvestav.mx
}

Información del artículo: recibido: abril de 2015, reevaluado: julio de 2015, aceptado: noviembre de 2015

\section{Resumen}

91\% de la energía que se consume en el mundo se suministra por hidrocarburos, los cuales también son una de las principales fuentes de ingreso económico de algunos países de Latinoamérica, incluyendo México. El problema de la dependencia hacia los hidrocarburos se puede agravar con el incremento en la demanda de energía debido al constante crecimiento de la población. Es por ello que las nuevas políticas en energía se orientan a diversificar las fuentes de energía, principalmente, al uso de las energías renovables. Una posible solución es el uso del hidrógeno como energético, que se puede obtener a partir de recursos renovables como la biomasa para generar energía limpia en pequeñas ciudades. Se ha demostrado que algunos grupos de bacterias fermentadoras, tienen la capacidad de generar hidrógeno a partir de azúcares simples. Se realizó un estudio cromatográfico para determinar la presencia de biogás en los gases producidos por la fermentación natural de la bebida mediante algunas bacterias. En adición, mediante imágenes de microscopia se caracterizaron las bacterias implicadas en los procesos fermentativos. Las muestras se tomaron del pulque, bebida alcohólica natural de origen prehispánico. Con estos estudios se demostró la factibilidad para el uso de este biogás para obtener energía e hidrógeno sin alterar las condiciones naturales de fermentación de la bebida.

\section{Descriptores:}

- pulque

- energía

- hidrógeno

- bacterias

- Zymomonas

- Saccharomyces 


\begin{abstract}
$91 \%$ of the energy consumed worldwide is supplied by hydrocarbons, which are also a major source of income for some of the Latin American countries, including Mexico. The problem is aggravated with the increase in the demand of energy due to the steady population growth. For this reason, the new energy policies are moving towards diversifying sources of energy, in particular, the use of renewable energy. One possible solution, is the use of hydrogen which can be obtained from renewable sources such as biomass to generate clean energy for small towns. It has been shown that some groups of fermentative bacteria have the ability to generate hydrogen from simple sugars. A chromatographic study was performed to determine the presence of biogas in the gases produced by the natural fermentation through some of the involved bacteria, and subsequently, by microscopy to characterize the bacteria images in fermentative processes. Samples were taken from the natural alcoholic drink pulque; of prehispanic origin. These studies demonstrated the feasibility of the use of this biogas to produce energy in the form of hydrogen without altering the natural fermentation conditions of the drink itself.
\end{abstract}

Keywords:

- pulque

- energy

- hydrogen

- bacteria

- Zymomonas

- Saccharomyces

\section{Introducción}

La materia prima para la producción de hidrógeno es la glucosa, que se obtiene a partir de celulosa presente en la biomasa, el proceso de obtención genera gastos operativos importantes, debido al costo de las enzimas necesarias para hidrolizar la celulosa en glucosa (Ozkan et al., 2001); por ello se puede partir de productos donde la carga de celulosa ya se encuentre degradada o no exista.

En México la bioenergía representa $8 \%$ del consumo de energía primaria. Los principales bioenergéticos empleados son el bagazo de caña para la generación eléctrica o térmica en la industria azucarera; por otro lado, la leña se utiliza fundamentalmente para la calefacción y cocción de alimentos. Entre los residuos bioenergéticos, se encuentran todos los residuos forestales y el biogás propio de la degradación de materia orgánica.

\section{Procesos para la producción de hidrógeno}

El hidrógeno es un energético secundario que puede producirse por medio de una gran variedad de métodos, estos se caracterizan por la fuente de energía primaria utilizada para obtenerlo.

En el estudio del impacto para la obtención de hidrógeno, se debe incluir el costo ambiental y social, ya que en las fuentes primarias para su obtención se incluyen recursos fósiles como el gas natural y el carbón, además de otras fuentes renovables como la biomasa, la energía solar, la eólica, la hidráulica y la nuclear. Las tecnologías de producción presentan una gran cantidad de alternativas como procesos químicos, biológicos, electrolíticos, fotolíticos y termoquímicos.
La investigación sobre el hidrógeno es un tema muy activo; Soria et al. (2001) estudian la obtención de hidrógeno a partir de biodigestores de líquidos orgánicos que producen metano y $\mathrm{CO}_{2}$. Buitrón y Carvajal (2009) utilizan aguas residuales de la industria del tequila para la producción de hidrógeno mediante procesos anaeróbicos, sin recurrir a la formación de metano; Vargas (2004) lo produce a partir de reformado de etanol, que es un alcohol presente en los fermentos de bebidas alcohólicas y algunos destilados.

Algunos grupos de bacterias como los géneros: Serratia, Enterobacter y Bacillus, producen butanodiol, etanol e hidrógeno mediante fermentación butanodiólica, que es un método bastante utilizado hoy en día. Los géneros Escherichia, Salmonel, Shigella, Proteus, Yersina, Photobacterium y Vibrio, producen una variedad de ácido (acético, láctico, fórmico) y etanol e hidrógeno por fermentación ácido mixta. Mediante fermentación butírica utilizando bacterias anaeróbicas de los géneros Clostridium y Sarcinase se obtienen elevados rendimientos de hidrógeno junto con ácido butírico, acético y dióxido de carbono. La fermentación de la acetona-butanol, utilizando Clostridium, es otra variante de este proceso. El género Rhodobacterspharoides se identifica para producir hidrógeno a partir de aguas de residuos ricas en nutrientes orgánicos de bajo peso molecular mediante fermentación (Noike y Mizuno, 2000).

Un esquema general del proceso de producción fermentativa de hidrógeno se basa en la siguiente reacción

$\mathrm{C}_{6} \mathrm{H}_{12} \mathrm{O}_{6}+2 \mathrm{H}_{2} \mathrm{O}---------->2 \mathrm{CH}_{3} \mathrm{COOH}+2 \mathrm{CO}_{2}+4 \mathrm{H}_{2}$ 
Este proceso es capaz de generar $0.5 \mathrm{~m}^{3}$ de hidrógeno por $\mathrm{kg}$ de hidrato de carbono utilizado.

Además de dichos sistemas fotosintéticos y fermentativos, también se han desarrollado sistemas mixtos que combinan diversos procesos a la vez (Kataoka et al., 1999).

\section{El pulque}

El pulque es una bebida tradicional mexicana que se obtiene por la fermentación de la savia azucarada conocida como aguamiel, esta se obtiene a partir de diferentes especies de maguey (Agave americana, A. atrovirens, A. feroz, A. mapisaga, A. salmiana) y existen 150 especies diferentes (Comisión Nacional para el conocimiento y uso de la Biodiversidad, CONABIO).

Estas plantas se encuentran en el valle de México, principalmente en Puebla e Hidalgo, así como el estado de México. La figura1 muestra la ubicación de las especies de maguey.

El maguey pulquero requiere aproximadamente diez años para alcanzar su madurez y poder aprovecharse. La etapa productiva de un maguey pulquero comienza cuando este se "capa", es decir, cuando se le corta el conjunto de pencas más tiernas del centro de la planta para que, al cabo de cuatro meses, comience a dar sus primeros litros de aguamiel. El periodo de producción del aguamiel dura generalmente de tres a cuatro meses y rinde, en promedio, unos 300 litros por planta. De la fermentación del aguamiel, que tarda menos de 24 horas, se obtiene la bebida alcohólica que conocemos como pulque. El contenido alcohólico depende del tiempo que haya fermentado. La concentración en grados Gay Lussac varía entre los 6 para pulques tiernos y los 20 para pulques fuertes (Lima, 1990).

La caracterización del contenido del pulque abarca varios trabajos de investigación: Correa et al. (2014) catalogaron la composición de pulque de origen prehispánico por su valor nutrimental, Valadez et al. (2012) realizaron la caracterización de bacterias formadoras de ácido láctico para analizar la relación entre estas, así como el lugar de obtención del pulque. Otra de las características que se estudiaron del pulque, es su contenido de alcohol y la relación que tiene con su contenido propio de bacterias (Cervantes y Pedroza, 2008). En esos trabajos se logró caracterizar al menos un grupo de bacterias propias del pulque Zymomonas y Saccharomyces.

Con base en lo anterior, el presente trabajo realizó un estudio cromatográfico para determinar la presencia de $\mathrm{H}_{2}$ en los gases producidos por la fermentación natural de algunas bacterias y posteriormente, mediante imágenes de microscopía se caracterizaron las bacterias que se implican en los procesos fermentativos. Asimismo, se realizó un análisis de la factibilidad del proceso de obtención del $\mathrm{H}_{2}$ a partir de la fermentación del pulque.

\section{Desarrollo}

Las muestras de pulque se obtuvieron en el Estado de México, en el pueblo de Tlalmanalco del municipio de Chalco, $19^{\circ} 8^{\prime} 48^{\prime \prime} \mathrm{N}, 98^{\circ} 37^{\prime} 58^{\prime \prime} \mathrm{W}$, que se encuentra a una altitud de 2,400 m s.n.m. Las muestras se colocaron en frascos de $200 \mathrm{ml}$, en los cuales se vertieron $100 \mathrm{ml}$ de líquido de cada una de las etapas (aguamiel, semilla, y contrapunta pulque).

El aguamiel es el líquido que escurre directamente de las pencas del maguey. Este es muy dulce y transparente y no presenta la consistencia viscosa del pulque ya fermentado o maduro. La semilla es un pulque con fermentación de dos semanas o más y es muy viscoso, con olor fuerte, parecido al vinagre. La contrapunta es un pulque de 24 horas de fermentación obtenido por una mezcla 1:1 de aguamiel y semilla.

El biogás generado a partir de cada muestra líquida, se analizó en un cromatógrafo del tipo Gas Chromatograph GC-8A, Shimadzu con detector de conductividad térmica equipado con columna capilar de Shin carbón. La muestra líquida se sometió a una rampa de calentamiento de $2^{\circ} \mathrm{C}$ cada minuto desde la temperatu-

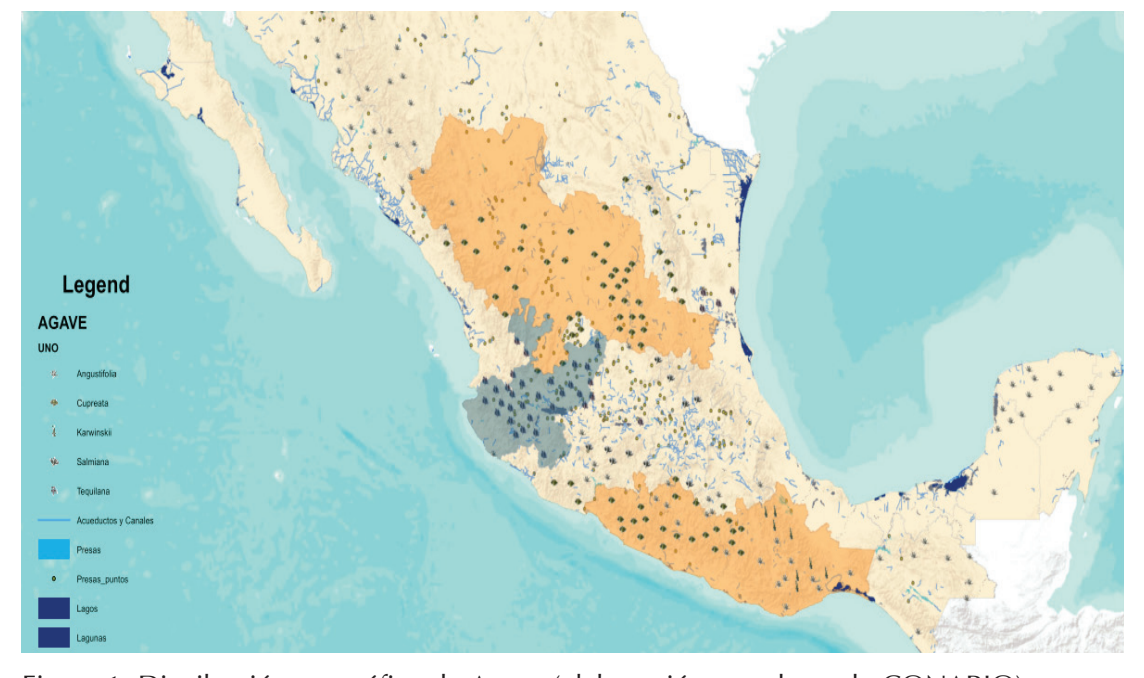

Figura 1. Distribución geográfica de Agave (elaboración con datos de CONABIO) 
ra ambiente que osciló entre 22 y $23^{\circ} \mathrm{C}$ hasta llegar a una temperatura de $50^{\circ} \mathrm{C}$ manteniéndola estable, durante el análisis de gas (15 min).

La rampa de calentamiento se utilizó para acelerar el proceso de fermentación y no afectar a las bacterias que podrían morir al sufrir un cambio brusco de temperatura.

Se tomaron muestras de los gases liberados en intervalos de tiempo de 0, 15,40 y 80 minutos. Asimismo, se realizó microscopia para las muestras líquidas, con un microscopio Olympus adaptado con cámara digital y filtro infrarrojo.

\section{Discusión y análisis de resultados}

En las muestras líquidas (semilla y contrapunta) se observa la presencia de hidrógeno liberado excepto en el aguamiel. En el pulque fermentado por dos días hay una presencia de $5 \%$ de hidrógeno del total de biogás producido por las muestras de $100 \mathrm{ml}$; en las muestras de pulque de fermentación por más de dos días, la concentración de $\mathrm{H}_{2}$ es de $5 \mu$ mol en promedio. La tabla 1 presenta la relación de producción de hidrógeno respecto al oxígeno y metano.

Tabla 1. Concentración de los diferentes gases obtenidos a partir de los cromatogramas de muestras de pulque $(200 \mathrm{ml})$, temperatura $50^{\circ} \mathrm{C}$, agitación $800 \mathrm{rpm}$

\begin{tabular}{|c|c|c|c|c|}
\hline \multirow{2}{*}{ Tiempo (min) } & \multicolumn{3}{|c|}{ Área } & \multirow{2}{*}{$\mu$ mol de $\mathrm{H}_{2}$} \\
\cline { 2 - 4 } & $\mathrm{H}_{2}$ & $\mathrm{O}_{2}$ & $\mathrm{CH}_{4}$ & \\
\hline 0 & 0.33 & 2.10 & 14 & 0.66 \\
\hline 15 & 1.10 & 1.99 & 39 & 2.20 \\
\hline 40 & 1.68 & 1.61 & 52 & 3.36 \\
\hline 80 & 2.00 & 1.51 & 55 & 4.00 \\
\hline
\end{tabular}

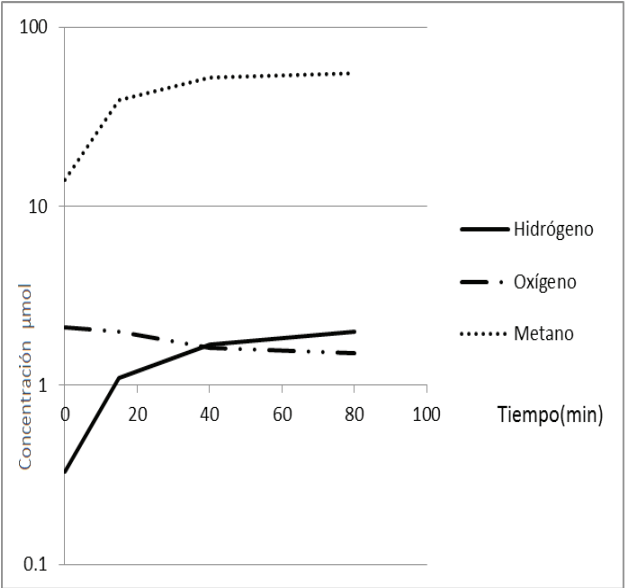

Figura 2. Concentración contra tiempo de los componentes del biogás de pulque contrapunta
En la tabla 1 se aprecia la baja cantidad de hidrógeno liberado en las muestras. Se observa un pequeño aumento en su formación hasta un límite (80 min) cuando se estabiliza, a diferencia del metano que se incrementa rápidamente. Las diferentes concentraciones de los componentes del biogás se pueden apreciar en la figura 2, que muestran la prevalencia del metano, donde se observa la similitud del comportamiento del metano y el hidrógeno, no así para el oxígeno que presenta un decrecimiento respecto al tiempo.

Se realizaron mediciones de contenido de hidrógeno para tres muestras de diferentes pulques, donde se encontró similitud en su composición, como se muestra en la figura 3.

La muestra $C$ es el aguamiel-pulque recolectado durante el mes de enero, época de frio y de lluvias, la muestra B se tomó de un maguey joven en la misma época y la muestra A se tomó durante los meses de marzo con mayor temperatura y sin lluvias.

El comportamiento es el mismo, aunque las cantidades varían entre sí debido a que la composición del pulque depende de diferentes factores como el tipo de suelo, clima y nivel de maduración de la planta; por ello, las muestras se tomaron del mismo sitio para evitar que estos factores generaran valores muy dispersos de producción de biogás, la muestra $\mathrm{B}$ se tomó de una planta joven de siete años (el promedio de maduración es de diez a doce años), la muestra $\mathrm{A}$ y $\mathrm{C}$ fueron de plantas adultas, los resultados difieren entre sí, pero conservan el patrón de producción de hidrógeno.

La cosecha se realizó en meses distintos durante el año, por lo que las condiciones climáticas difieren. En época de sequía el maguey trata de conservar su humedad, que también sucede si este se encuentra sembrado en terrenos áridos o semiáridos, lo que genera aguamiel más espeso y con más carga de bacterias, esto limita la producción de hidrógeno al consumirse más rápido por las bacterias y al tener menor alimento. En los meses de

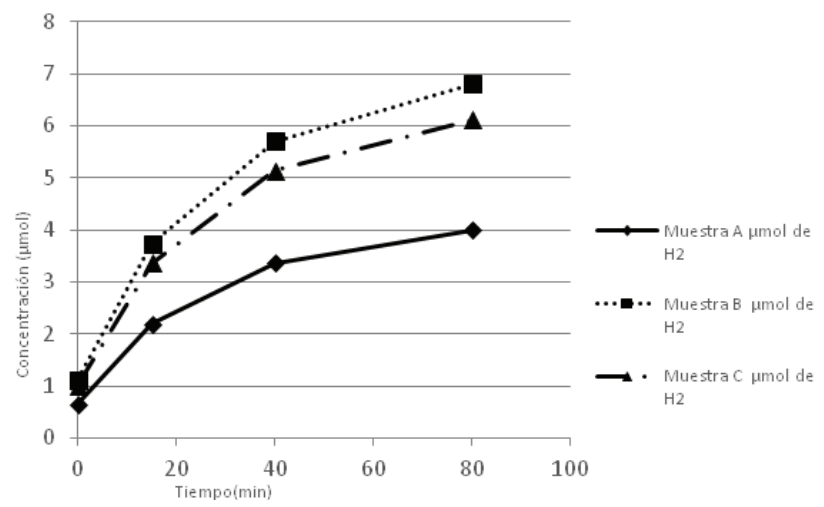

Figura 3. Producción de $\mathrm{H}_{2}$ con respecto al tiempo 
lluvia el maguey produce un aguamiel más azucarado y líquido, que genera más alimento para las bacterias y aumenta la cantidad de hidrógeno producido.

Los estudios realizados en las muestras arrojan una escasa presencia de hidrógeno de 12 micromoles, que es la mayor concentración, debido a que no se detuvo el proceso de fermentación. Por ello, las bacterias Metanogenicas Hidrogenofilicas presentes en la mezcla realizaron su proceso natural, agotando el hidrógeno y produciendo metano. Este tipo de bacterias son comunes en biodigestores, ya que al no detener el proceso no se modifica la bebida natural, por otro lado, si este proceso se detiene, la producción de hidrógeno sería mayor desde el momento de la adición de la semilla donde no se agota el suministro de azúcares.

Al realizar el calentamiento se aceleró el ciclo de vida de las bacterias incrementando aún más la presencia de metano, ya que los estudios dan evidencia de una mayor producción de este, el cual en sí mismo se utiliza como combustible en generadores de electricidad, lo cual daría un insumo utilizándolo como biogás.

Mediante el uso del microscopio óptico se lograron identificar comunidades de bacterias pertenecientes al pulque de los géneros Saccharomyces sp, Zymomonas $\mathrm{sp}$, y Lactobacillus sp., como se muestra en las figuras 4 y 5 .

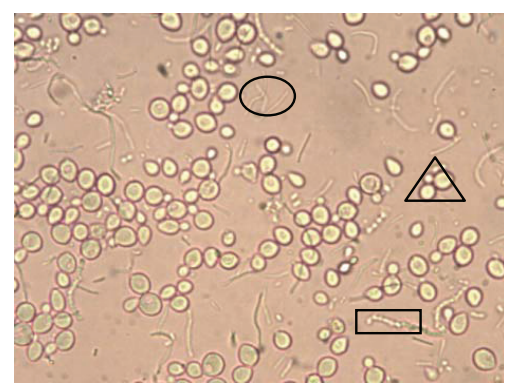

Figura 4. Muestra de bacterias en pulque, muestra saturada objetivo 40X, caracterización del género Zymomonas (ovalo), Saccharomyces (triangulo) y Leuconostoc (rectángulo)

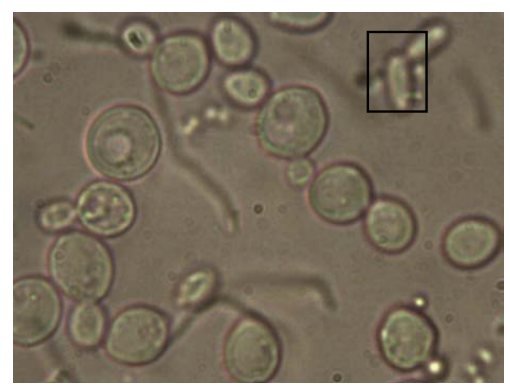

Figura 5. Muestra de bastecerías en pulque muestra saturada objetivo 100X, Zymomonas, Saccharomyces, Leuconostoc y Salmonella
Las bacterias pertenecientes a los géneros Escherichia, Salmonella, Shigella, Proteus, Yersinia, Vibrio y Photobacterium presentan el enzima formicohidrogenilasa que rompe la molécula de ácido en dióxido de carbono e hidrógeno, en las muestras se logró encontrar Salmonella, aunque la presencia de esta indica cierta insalubridad en el proceso.

\section{Conclusiones}

Las concentraciones de hidrógeno, aun cuando en todas las muestras dieron valores escasos, se observa la presencia del gas sin alterar la bebida natural. Al calentar las muestras de pulque se aceleró el proceso de fermentación que produce hidrógeno, que a su vez, lo consume de forma natural gracias a los procesos metabólicos de las bacterias. Esto lo constatamos mediante el monitoreo cromatográfico, donde se mostró mayor presencia de metano y una disminución en la producción de hidrógeno. Cabe señalar que las muestras no se dejaron más tiempo al llegar a un equilibro, donde ya no hay gasto de hidrógeno ni producción de metano considerable.

El metano generado puede utilizarse para producción de hidrógeno mediante el proceso de craqueo catalítico, por lo que no se descarta esta forma de obtención; el metano se puede recuperar y con ello producir energía, recordando que el metano es un gas de efecto invernadero, con lo que se aportaría la disminución de este en el ambiente.

\section{Agradecimientos}

Agradecemos al CONACyT, México por la beca (Núm. 221931) que apoyó este trabajo de investigación.

\section{Referencias}

Buitrón G. y Carvajal M. Producción de hidrógeno a partir de aguas residuales. Revista Digital Universitaria, volumen 10 (número 6), agosto de 2009 [en línea] [fecha de consulta: 2 de septiembre de 20011]. Disponible en: http://www.revista. unam.mx/vol.10/num8/art50/art50.pdf

Cervantes-Contreras M. y Pedroza A.M. Caracterización microbiológica del pulque y cuantificación de su contenido de etanol mediante espectroscopia Raman. Superficies y Vacío, volumen 20 (número 3), marzo de 2008: 1-5.

Correa-Ascencio M., Roberston I.G., Cabrera-Cortés O., Cabrera-Castro R., Evershed R.P. Pulque production from fermented agave sap as a dietary supplement in Prehispanic Mesoamerica,Proceedings of the National Academy of Sciences (PNAS), volumen 111, Núm. 39, 20 de septiembre, 2014. 
Kataoka N., Miya A., Kiriyama K. Studies on hydrogen production system using microoganisms, Ebara Engineering Review, Núm. 183, 1999.

Lima-Gonçalves de O. Pulque, balché y pajauaru en la etnobiología de las bebidas y de los alimentos fermentados, $1^{\text {a }}$ ed., México, Fondo de Cultura Económica, 1990, pp. 100-483.

Noike T. y Mizuno O. Hydrogen fermentation of organic municipal wastes. Water Science \& Technology, volumen 42 (número 12), diciembre de 2000:155-162.

Ozkan M., Desai S.G., Zhang Y., Stevenson D.M., Beane J., White E.A., Guerinot M.L., Lynd L. Characterization of 13 newly isolated strains of anaerobic cellulolytic, thermophilic bacteria. J. Ind. Microbiol. Biotechnol, volumen 27 (número 5), octubre de 2001: 275-280.

Soria F., Ferrera C., Etchevers J., Gonzales A., Trinidad J.B. Biodigestion of hog slurry to produce. Biomanure, volumen 19 (número 4), septiembre de 2001: 353-362.

Valadez-Blanco R., Bravo-Villa G., Santos-Sánchez N.F., VelascoAlmendarez S. I., Montville T.J. The artisanal production of pulque, a traditional beverage of the mexican highlands. Probiotics \&Antimicro, Prot4:140-144, 2012.

Vargas J.C., Sternenberg F., Roger A.C., Kiennemann A. Steam reforming of bioethanol on Coo/Ce-Zr-Co and $\mathrm{Coo} / \mathrm{Ce}-\mathrm{Zr}$ catalysts a comparison between cobalt integration and cobalt impregnation. Chem. Eng. Trans, volumen 4, 2004: 247-252.

\section{Bibliografía}

Bösl B., Mata-Sandoval J.C., Eckermann A. Energías renovables para el desarrollo sustentable en México, Secretaría de Energía, México, 2006.

Comisión Nacional para el Conocimiento y Uso de la Biodiversidad CONABIO [en línea] [fecha de consulta: 30 de septiembre 2011]. Disponible en: http://www.conabio.gob.mx/
González-Ávila M.E. Producción de bioenergía en el norte de México: tan lejos y tan cerca. Frontera norte, volumen 21 (número 41) México, 2009.

International Energy Agency, IEA, Datos estadísticos, 2012 [en línea]. Disponible en http://www.iea.org/stats/index.asp

Navarro R., Del Valle F. Photocatalytic water splitting under visible light: Concept and catalysts development. Advances in Chemical Engineering, volumen 36, 2009: 111.

Ortega-Valencia E., François-Lacouture J.L. Producción de hidrógeno mediante energía nuclear, un escenario sostenible en México, LAS/ANS Symposium, XVIII Congreso Anual de la SNM, 2007.

Ramachandran R., Menont R.K. An overview of industrial uses of hydrogen. International Journal Hydrogen Energy, volumen 23 (número 7), 1998: 593-598.

Sánchez-Marroquín A., Larios C., Vierna L. Estudios sobre la microbiología del pulque. XIX. Elaboración de la bebida mediante cultivos puros, en planta piloto. Rev Latinoam Microbiol Parasito, volumen 19, 1967: 83-85.

\section{Este artículo se cita:}

\section{Citación estilo Chicago}

Rivera-Vargas, Griselda Argelia, Yasuhiro Matsumoto-Kuwabara, Rafael Baquero-Parra. Análisis para la obtención de hidrógeno a partir de biogás proveniente de la fermentación de bebidas naturales. Ingeniería Investigación y Tecnología, XVII, 02 (2016): 251-256.

\section{Citación estilo ISO 690}

Rivera-Vargas G.A., Matsumoto-Kuwabara Y., Baquero-Parra R. Análisis para la obtención de hidrógeno a partir de biogás proveniente de la fermentación de bebidas naturales. Ingeniería Investigación y Tecnología, volumen XVII (número 2), abril-junio 2016: 251-256.

\section{Semblanzas de los autores}

Griselda Argelia Rivera-Vargas. Estudiante de doctorado del Programa en Doctorado en Desarrollo Científico y Tecnológico para la Sociedad de CINVESTAV del Instituto Politécnico Nacional.

Yasuhiro Matsumoto-Kuwabara. Es ingeniero en comunicaciones y electrónica por la ESIME-IPN, asimismo doctor por la Facultad de Ciencias de Ingeniería de la Universidad de Osaka. Se interesa por los materiales, dispositivos semiconductores y la nanotecnología. Trabaja con las celdas solares y en el aprovechamiento de la energía solar mediante sistemas fotovoltaicos. Tiene 40 artículos en revistas de prestigio y más de 150 trabajos publicados en congresos internacionales. Actualmente coordina la Red de Fuentes de Energía del CONACyT. Posee el Premio Nacional de Energía Renovable de la Secretaria de Energía.

Rafael Baquero-Parra. Es doctor en ciencias por el Cinvestav. Cuenta con un posdoctorado: U. Mc Master, en Canadá. Tiene 80 trabajos en revistas, es autor de 6 libros y editor de dos. Ha dirigido más de 40 tesis. Se especializa en: superconductividad y física de superficies. Fue vicepresidente de la SMF, actualmente es académico de la AMC, "Ciudadano Distinguido" de la Ciudad de Puebla, "Miembro de Honor" de la Sociedad Colombiana de Física, "Miembro de Mérito" de la Sociedad Cubana de Física, "Investigador Distinguido" por el Ayuntamiento de Puebla y "Académico Correspondiente" de la Academia Colombiana de Ciencias Exactas, Físicas y Naturales. 